\title{
Elementos para a concepção de um parque fluvial com base no patrimônio rural disperso na região do Médio Tietê
}

\section{André Munhoz de Argollo Ferrão}

Engenheiro Civil, Arquiteto e Urbanista, Doutor em Arquitetura e Urbanismo. Professor Livre Docente do Departamento de Recursos Hídricos, FEC-Unicamp. Coordenador do Labore. Campinas, [SP], Brasil. <argollo@fec.unicamp.br>.

\section{Fernando Vicente Oliveira}

Arquiteto e Urbanista, Mestre em Urbanismo. Finalizou o Doutorando em Engenharia Civil, Laboratório de Engenharia de Empreendimentos (Labore), Área de Recursos Hídricos, Energéticos e Ambientais. FEC-Unicamp. Itu [SP], Brasil.

\section{Resumo}

Caracteriza-se neste artigo o patrimônio rural como um componente fundamental da paisagem na Bacia Hidrográfica do Sorocaba Médio Tietê (BHSMT), especialmente entre as cidades de Cabreúva, Itu, Salto e Porto Feliz (estado de São Paulo, Brasil). Destacam-se as sedes das principais fazendas históricas da região como elementos primordiais para a concepção de um parque fluvial no Médio Tietê. Toma-se como referência o projeto do parque fluvial do Baixo Llobregat, na Catalunha. Compara-se o contexto da região paulista com o da região catalã. Ao final, apresenta-se em forma de uma carta geográfica os elementos enunciados no Título do trabalho.

\section{Palavras-chave}

Arquitetura Rural, planejamento regional, desenvolvimento local, patrimônio cultural, parque fluvial.

\section{Elements for designing a fluvial park based on dispersed rural heritage in the Middle Tietê}

\begin{abstract}
It is characterized in this article the rural heritage as a fundamental component of landscape in the Basin "Sorocaba Middle Tietê" (BHSMT), especially between the towns of Cabreúva, Itu, Salto and Porto Feliz (state of São Paulo, Brazil). Stand out the headquarters of the historical farms in the region as primordial elements for designing a river park in the "Middle Tietê". Take as the reference the project of fluvial park of the "Lower Llobregat", Catalonia. It compares the context of the São Paulo region with the Catalan region. At the end, comes in the form of a geographic map the elements mentioned in Title of work.
\end{abstract}

\section{Keywords}

Rural Architecture, regional planning, local development, cultural heritage, river park. 


\section{Introdução}

O objetivo deste artigo é contribuir para a discussão sobre conceitos de desenvolvimento regional, a partir da compreensão e aplicação em projetos como o de um parque fluvial, nas regiões de grande potencial para isso, reunindo áreas de interesse histórico-cultural e ambiental, como são, especificamente, as áreas das fazendas do período da cana-deaçúcar e do café, séculos XVIII e XIX, situadas na Bacia Hidrográfica do Sorocaba Médio Tietê (BHSMT), na região de Itu, estado de São Paulo, Brasil, porção territorial tomada como objeto deste estudo.

As fazendas da região de Itu, assim como as de outras regiões do mesmo período, com suas construções centenárias compondo uma paisagem característica fortemente baseada no complexo produtivo correspondente a cada época, passaram por diferentes processos de modernização - tanto em suas edificações como em seu maquinário - principalmente em decorrência do constante fluxo de comércio entre Brasil e Europa, acompanhando as mudanças tecnológicas, econômicas e sociais.

No Brasil, a sociedade rural dos séculos XVIII e XIX era detentora de um processo de produção agrícola baseado na monocultura, adequado ao contexto de cada período e região em que se instalou, primeiro com a cana (principalmente no Nordeste) depois com o café (principalmente no Sudeste), que movimentava sua economia, de maneira a refletir-se diretamente sobre a sua arquitetura industrial (no caso, agroindustrial, ou - marcantemente - rural), e na construção civil (cidade e campo).

As transformações nas fazendas remanescentes da região de Cabreúva, Itu, Salto e Porto Feliz, na BHSMT, constituem, portanto, o universo desta pesquisa, que pretende mostrar como é que o seu patrimônio se apresenta contemporaneamente, e propor meios para sua conservação, levando-se em conta o conjunto das propriedades rurais e suas características, cujo aspecto principal em termos de localização é justamente o fato de terem sido implantadas ao longo do eixo dos rios Tietê e Sorocaba. Assim, a presença do curso d'água impõe a necessidade de um olhar diferenciado sobre o patrimônio existente nessas fazendas, que integram uma determinada porção territorial: a bacia hidrográfica.

O inventário resultante de um levantamento cuidadoso nessa região pode contribuir para estabelecer parâmetros e indicar procedimentos para a manutenção do valioso patrimônio rural ali disperso, a fim de se promoverem meios para a conservação e o uso apropriado destes imóveis, sem necessariamente submetê-los à especulação imobiliária, que muitas vezes modifica a paisagem de forma drástica.

Uma importante referência deste trabalho é a Pesquisa que Joaquín Sabaté Bel e J. Mark Schuster desenvolveram por ocasião da realização de um projeto para o eixo do rio Llobregat, na Catalunha (Espanha), e com isso fomentaram uma importante discussão conceitual sobre paisagem cultural e desenvolvimento regional, registrada no documento intitulado: "Projectant I' eix del Llobregat. Paisage cultural i desenvolupament regional" $(2001)^{1}$.

O estudo de Sabaté e Schuster (2001) considera diferentes porções do território em que alguns de seus trechos são mais propícios ao desenvolvimento de um parque que valorize o

\footnotetext{
1 Projeto desenvolvido em conjunto por pesquisadores do "Departamento de Urbanismo e Ordenación Territorial" da
} 
patrimônio natural e cultural determinado pelo eixo do rio. Ressalte-se o fato de que o conceito dos autores se refere a uma experiência de requalificação urbanística e não apenas patrimonial, portanto, o enfoque voltado para o desenvolvimento regional se destaca dentre as principais premissas do projeto. $O$ contexto em que se desenrola o projeto tem muito de caráter educativo, de valorização da memória local, e de estabelecimento de um ou mais percursos.

A região catalã tomada como referência neste estudo apresenta cidades com perfis semelhantes à região paulista foco desta pesquisa. Tratam-se de cidades de médio porte, sujeitas a pressões que implicam em situações desde a especulação imobiliária até a implantação de atividades não compatíveis com a área.

As transformações ocorridas no território da região catalã permitiram a requalificação de áreas agrícolas e industrializadas abandonadas ao longo do curso do rio Llobregat, bem como, de áreas destinadas à preservação ambiental, todas bem dotadas de infra-estrutura, mas ainda subutilizadas nos seus vales e margens.

Todavia o estudo deste caso internacional demandou pesquisa em revistas especializadas publicadas em diferentes países ${ }^{2}$, além de panfletos, folders e folhetos específicos, material acadêmico e não-acadêmico coletados pelos autores em visitas à região ${ }^{3}$. Também se utilizou de pesquisa em sítios eletrônicos para a elaboração do perfil geoeconômico da área estudada, destacando-se aspectos pertinentes à discussão do caso analisado ${ }^{4}$. Tratou-se de procurar entender a fundo a experiência daquela região.

Além desses mencionados documentos, este trabalho apoiou-se em dados e informações recolhidas de análise cartográfica e pesquisa de campo na bacia do Médio Tietê, para se proceder às análises comparativas pertinentes. Muita informação foi extraída a partir de uma atenta leitura da bacia hidrográfica, apoiada em cartas geográficas existentes. No entanto, as cartas obtidas como resultados do estudo foram produzidas por Fernando Vicente Oliveira em 2010 e 2011, a partir de levantamentos in loco e da leitura e compilação das referências históricas mais evidentes dentro das fazendas estudadas. Não se pretendeu apresentar uma discussão sobre o passado ou sobre aquilo que foi destruído, mas sim explicitar o que ainda resta como patrimônio e formas de melhor utilizá-lo.

Semelhante ao conceito de Parque Fluvial, há também na Inglaterra o conceito de Parques Rurais, que foi dado pelo Ato $1968^{5}$. Os parques têm por objetivo prover áreas abertas para recreação, aliviar as pressões de crescimento urbano, além de oferecer alternativas diferenciadas à transformação de todas as áreas verdes em parques nacionais.

Um dos propósitos para a criação dos parques pelas autoridades de planejamento urbano inglesas é promover melhoria em áreas para recreação, para o público em geral e, portanto, devem ser localizados próximos de áreas urbanas ou dotados de construções que facilitem

\footnotetext{
2 Principalmente a Espanha (particularmente a região da Catalunha), e os Estados Unidos (particularmente os trabalhos desenvolvidos no Departamento de Planejamento Regional do M.I.T.).

3 André Argollo em 2004, 2006 e 2008; e Fernando Oliveira em 2010.

4 Além disso, o Labore / FEC-Unicamp (Laboratório de Engenharia de Empreendimentos da Área de Recursos Hídricos, Energéticos e Ambientais / Faculdade de Engenharia Civil, Arquitetura e Urbanismo da Unicamp) participa do mesmo Grupo de Pesquisa do L.I.P.C. (Laboratorio Internacional de Paisajes Culturales) sediado em Barcelona (ETSAB-UPC), sendo André Argollo um de seus fundadores, em 2004, sob coordenação de Joaquín Sabaté Bel. Finalmente, com a criação da Rede Conpadre em 2010 - "Conexões entre Patrimônio Ambiental e Desenvolvimento Regional" - a integração entre as pesquisas desenvolvidas no Labore / FEC-Unicamp com as do L.I.P.C. tornou-se mais intensa e contínua. Ver: <www.conpadre.org>.

${ }^{5}$ Countryside Act 1968 - legislation.gov.uk. Disponível em : <www.legislation.gov.uk/ukpga/1968>.
} 
a adequação de infra-estrutura ${ }^{6}$. Há a necessidade de cooperação mútua e do aditivo rural, assim o poder público, ligado à área urbana, pode contribuir para sua execução.

No Brasil, pesquisadores do Labore-Unicamp desenvolvem no âmbito da linha de pesquisa em "Planejamento Regional, Patrimônio e Paisagem", desde 2006, estudos de aplicação dos conceitos utilizados na Europa e nos Estados Unidos para o projeto e a criação de parques como elementos de ordenação territorial, em cada caso levando-se em conta a necessidade de integração do patrimônio ambiental para o desenvolvimento regional ${ }^{7}$.

Geralmente a disposição dos diferentes espaços que compõem os parques deve ser adequada a uma arquitetura e engenharia concebidas especificamente para cada perfil, dada a tipologia do parque em cada caso. A começar por uma indispensável infra-estrutura para trilhas, áreas de estacionamento, mesas para picnic, conveniências, quiosques de informação e possivelmente a provisão de áreas para praças de alimentação e sanitários. Desta forma, muitos parques, tanto na Espanha como na Inglaterra, se constituem como exemplos em que se destacam conceitos projetuais como características que imprimem valor à presença do rio ou de uma área agrícola, ou ainda, de um conjunto patrimonial.

A partir da observação de vários parques constituídos na Espanha e na Inglaterra é possível inferir que o significado cultural e a função social do patrimônio ligado a eles devem ser vistos sob o aspecto do grupo ao qual ele pertence, não sendo apenas reflexo das políticas públicas impostas de maneira vertical e das posturas adotadas pelos órgãos de preservação e proteção. Trata-se de uma visão ampliada sobre os valores da comunidade em que se inserem, a fim de se conservar e proteger seu patrimônio e sua história, convertendo-se assim em objeto de tradição e de respeito.

\section{Contextualização do desenvolvimento regional no Médio Tietê}

Com a expansão dos núcleos urbanos na região a partir do século XVIII, a mão de obra que se utilizava era a escrava, vinda da África, pois o nativo indígena não era adaptável a este tipo de trabalho. A produção aurífera tinha seu centro em Minas Gerais, mas com seu declínio, novas formas de economia passaram a se intensificar em outras regiões. Nas terras do Médio Tietê eram produtoras de cana-de-açúcar, mas com seu declínio, o café surge como nova opção para a economia da região.

Com o crescimento da economia baseada na produção de café, surgem na região do Médio Tietê novos métodos de construção, diferenciados e apropriados para as instalações industriais das unidades de produção cafeeira, que se modernizam e começam a adotar para as casas-sede e também para as residências senhoriais nas cidades - o gosto europeu no modo de se viver e morar. No início, as casas assim como as demais construções complementares nas fazendas eram feitas em taipa de pilão (paredes externas) e taipa de mão (paredes internas), técnicas conhecidas na península lbérica, utilizadas pelos mouros, do norte da África, introduzidas no Brasil, assim como em toda a América Latina com a colonização. Posteriormente, as adaptações em cada região enriqueciam a arquitetura vernacular, por exemplo, com o uso associado do adobe (tijolo de barro seco ao sol) e do

\footnotetext{
${ }^{6}$ Este estudo foi desenvolvido por Fernando Vicente Oliveira, no período em que realizou o seu mestrado na University of Liverpool, Inglaterra, em 1999.

${ }^{7}$ Ver, por exemplo: Braga \& Argollo Ferrão (2010). Arquitetura da Produção Rural: o Parque Agrário como uma possibilidade de valorização dos recursos patrimoniais para os Perímetros Irrigados do Nordeste do Brasil. Ver também: Oliveira \& Argollo Ferrão (2012). Caracterização do patrimônio ambiental em parques na Bacia Hidrográfica do Sorocaba Médio Tietê: cidades de Cabreúva, Itu, Salto e Porto Feliz (São Paulo).
} 
pau-a-pique (ou taipa de mão: vedação feita a partir do enchimento dos vãos de uma trama de madeira com barro em estado plástico, não sendo estrutural).

Casas construídas com estas técnicas ainda subsistem na região, e podem ser facilmente encontradas para observação. Datadas do período oitocentista, com seus programas de estar e receber baseados na existência dos alpendres, capelas e serviços externos. A estrutura austera era composta de telhados em quatro águas, beirais com cachorros e janelas de madeira com pouca ornamentação. Sucintamente, este era o aspecto tanto das casas rurais como urbanas do período. Diversos autores ${ }^{8}$ descrevem detalhadamente as características da construção rural oitocentista, entretanto, o objetivo aqui é numerar e caracterizar a composição do conjunto.

Ao longo do século XIX, os espaços internos das construções foram se modificando e novas formas de viver foram sendo agregadas ao cotidiano das fazendas. Há a inclusão dos sanitários para dentro das casas, a adoção de janelas com venezianas e vidros, a alternativa dos telhados escondidos por frontões e platibandas, e as fachadas ganham ornamentações dos mais variados estilos. A terra batida paulatinamente deixa de ser utilizada, pois com a Abolição (em 1988) e a introdução da mão de obra europeia (já no início da década de 1880), diferentes materiais e técnicas construtivas passam a ser preferíveis, por serem mais sofisticadas e modernas, como a alvenaria de tijolo queimado, a telha francesa, e as argamassas de cimento ${ }^{9}$.

Atualmente ainda resta um rico patrimônio arquitetônico nos vales da BHSMT. No entanto, novas atividades econômicas precisam ser adequadas sem danificar a malha patrimonial preexistente ou o distinto caráter paisagístico da área agrícola e dos elementos que tornam a região atraente. É importante ressaltar que a conservação destes locais pelos seus proprietários é onerosa, e as atividades agrícolas têm sido abandonadas ou substituídas por outras muito diferentes, certamente mais rentáveis.

Da mesma forma que no período de transição da cana-de-açúcar para o café, pode-se observar na região uma significativa alteração no modo de se morar e viver dentro destas fazendas, nos dias de hoje, as quais passam a contar com modernas instalações, para acomodar os proprietários, turistas e visitantes, em muitos casos, induzindo à mudança da estrutura da residência senhorial. Fica, portanto, uma reflexão: Como acomodar esta nova modernidade?

Este movimento todo torna-se bem mais lógico se pensado de maneira integrada, no contexto de um parque fluvial, ou seja, a partir de um plano diretor que defina regras de implantação de novos empreendimentos e o uso do solo, de tal modo que se favoreça o desenvolvimento local em conjunto, ou, baseado numa coevolução com o desenvolvimento regional. As propriedades rurais são atraentes e propícias a uma enorme gama de atividades econômicas, porém, ao mesmo tempo, esbarram em limites e problemas decorrentes do seu caráter patrimonial, histórico ou cultural, e também, da malha agrária conformada na região, difícil de ser alterada ou adaptada, o que pode se tornar uma barreira intransponível para o desenvolvimento local sustentável adaptado a uma nova realidade.

Em 2010 e 2011, Fernando Oliveira visitou as 22 fazendas localizadas na região do Médio Tietê, eleitas pelos autores deste estudo como potencialmente adaptáveis ao papel de unidades de interpretação de um parque fluvial. Cada uma compõe o conjunto do mosaico

\footnotetext{
8 Para se aprofundar mais nesta questão consultar autores como Sylvio de Vasconcelos, Carlos Alberto Cerqueira Lemos, Benedito Lima de Toledo, Luis Saia entre outros.

9 Da mesma maneira, há diversos autores que trabalham a mesma questão, não sendo aqui objeto do estudo.
} 
do parque proposto para a BHSMT. Nesse momento, não se pretende apontar uma forma de uso ou de atividade para cada unidade, mas sim, tratar a questão em forma de percurso, pelo do eixo do rio Tietê. Foi possível, a partir deste levantamento, apontar em mosaico o imenso valor de um patrimônio rural disperso, eloquente, presente na região, e assim promover discussões contínuas a fim de fomentar reflexões para o melhor uso dentro de cada potencialidade, em tais unidades. Ver Quadro 1.

Quadro 1. Fazendas do Médio Tietê, com potencial de se enquadrarem como unidades de interpretação de um parque fluvial, concebido para a região.

Fazenda Pau D'Alho. Situada no bairro do Aprotrebu, erguida entre 1730 e 1750, às margens do rio Tietê e da "Estrada Imperial". Hoje propriedade particular. Conserva a planta original de feição bandeirista.

Fazenda da Serra. Conjunto de taipa, com acréscimos em pedra e tijolos. Elementos marcantes são a roda d'água e a tulha, fazenda do período do café na região. A capela é de 1925 . Hoje vive de turismo e comércio de chocolates e sorvetes.

Fazenda Paraíso. Mantêm-se todo o conjunto arquitetônico, murado, com a sede senhorial do século XIX. Senzala destruída. Há terreiros, roda d'água e casas de beneficiamento de café, além de antigas instalações de uma indústria cerâmica. Hoje é propriedade particular, sem uso turístico.

Fazenda São José. Situada às margens da rodovia Dom Gabriel P. Couto, no bairro do Pedregulho, a nove quilômetros de Itu. Possui uma grande casa de máquinas, terreiros, tulhas, todos em total abandono. A casa sede é do final do século XIX, em tijolo e ornamentos de feições neoclássicas.

Fazenda Nova América. Situada no bairro do Pedregulho, é do final do século XIX tem em seu interior fogão de lenha, lareira, e banheira originais. À frente da casa sede situam-se tulhas, casa de maquinas e capela erguida em data posterior. Foi cenário de novelas da extinta TV Tupi. Hoje se encontra em total abandono.

Fazenda Floresta. Situa-se próxima à fazenda Concórdia, recentemente restaurada. Construção de taipa, mas com feições do período cafeeiro, da segunda metade do século XIX. A casa tem planta de feições bandeiristas, mas sofreu alterações com o decorrer do tempo.

Fazenda Limoeiro da Concórdia. Situada nas proximidades da capela de São Francisco, no bairro do Pedregulho, é uma fazenda do século XVIII, de feições bandeiristas e ainda há um muro em taipa, casa de maquinas e tulha de café. Foi uma das maiores produtoras de café e gado da região. Hoje é aproveitada para uso turístico, com armazém de 1901 e bar.

Fazenda Capoava (antiga Japão). Construção do século XVIII, onde iniciou-se o ciclo canavieiro. Casarão bandeirista com alpendre de meados de 1750 , construído em taipa de pilão, com capela anexa ao alpendre. Encontra-se muito bem conservada e hoje se dedica ao turismo rural.

Fazenda Cana Verde. Construção de 1881, representativa do ciclo do café na região. A fazenda possui instalações de tijolo para tratamento de café, com um aqueduto de dois quilômetros que move roda d'água de ferro de sete metros de diâmetro utilizada para máquinas de beneficiar café. Sede da fazenda mostra intervenções posteriores, mas nota-se a construção de feição bandeirista.

Fazenda Pirahy. Conjunto de taipa de pilão, sendo a sede uma casa de tradição bandeirista, com acréscimos de um sobrado de pau-a-pique, da segunda metade do século XIX. Possui fosso, roda d'água e um alambique de cachaça ainda preservado. Tudo indica que se tratava de um engenho de açúcar.

Fazenda Monte Belo. Construção do século XVIII, em taipa de pilão, abriga a casa sede, terreiros e a casa de maquinas da época do café. Atualmente dedica-se à criação de gado.

Fazenda da Ponte. Construção do século XVIII, situada em uma encosta a cerca de 100 metros da margem do rio Tietê, no Bairro Pedregulho. Propriedade particular que se dedica à criação de cavalos. Tem um valioso acervo em mobília e objetos de arte.

Fazenda Vassoural. Construção do século XIX, em estilo bandeirista, mantém terreiros, o tanque, o secador e a tulha da época.

Fazenda Jurumirim. Situa-se na estrada de terra ente Cabreúva-Itu, pouco acima da ponte sobre o ribeirão do Taboão. Propriedade particular, constituída de casa térrea de taipa e tijolo, de feições bandeiristas pela presença do alpendre frontal. Pertence ao período cafeeiro, pois tem um grande terreiro. A bandeira da porta traz a data de 1890 e as iniciais F.C.L. (Francisco Correa Leite) do antigo proprietário, mas atribui-se a casa ao século XVIII. Tem ampla caixilharia e várias janelas de vista para os dois terreiros, hoje feitos jardins.

ARGOLLO FERRÃO, A. M.; OLIVEIRA, F. V. Elementos para a concepção de um parque fluvial com base no patrimônio rural disperso na região do Médio Tietê. Labor \& Engenho, Campinas [Brasil] v. 6, n. 4, p. 61-71, 2012. Disponível em: $<w w w . c o n p a d r e . o r g>$ e <www.labore.fec.unicamp.br>. 
Fazenda Rosário. Construção do século XVIII, em estilo bandeirista, preservado até os dias de hoje, foi uma das maiores produtoras de açúcar da região. Atualmente promove cavalgada na lua cheia, eventos educacionais e noites de seresta.

Fazenda Conceição. Construção do século XVIII, estilo bandeirista, da época da cana-de-açúcar.

Propriedade particular, em excelente estado de conservação.

Fazenda Engenho D’Água. Situada na margem direita do rio Tietê, próximo a Porto Feliz (município da região), com casa construída de tijolo, de aparência anterior a 1890.

Fazenda Água Branca. Bairro do Pedregulho, Construção do século XIX, cafeeira. Hoje propriedade rural particular, envolvida por vegetação densa.

Fazenda Ingá-Mirim. Construção do século XIX. Dedicava-se à cultura de cana, café e do algodão. Propriedade particular sem uso turístico.

Fazenda Portela. Construção do século XIX, do ciclo cafeeiro, atualmente pertence ao condomínio Portela.

Fazenda Pirapitingui. Construção de 1751, em estilo bandeirista, foi bastante modificada recebendo um terreiro de café à sua frente. $O$ telhado foi recentemente refeito com telhas contemporâneas.

Fazenda Vaccary. Fazenda do fim do século XIX, de café, se situa em frente ao rio Tietê, hoje propriedade particular.

\section{Concepção de um parque fluvial com base no patrimônio rural da região do Médio Tietê: questões de planejamento para o desenvolvimento local}

As fazendas históricas elencadas no Quadro 1 aparecem como um grupo de características próprias, que possui um grande potencial para alavancar o desenvolvimento local, a partir do estabelecimento de diretrizes de uso e ocupação do solo, seja com o enfoque de serviços, comércio ou mesmo turístico e de lazer. Assim, elas podem conquistar a auto suficiência econômica, sem necessariamente se submeterem à especulação imobiliária.

Larkham (1996) afirmou que "toda atividade humana produz história. No entanto, apenas alguns locais contêm uma densidade de documentos que despertam o interesse de visitantes". É o que normalmente se designa por sítios históricos.

São diversos os parâmetros utilizados internacionalmente para se considerar determinados edifícios, conjuntos edificados, cidades ou áreas como de valor histórico. Neste caso específico, foram as características construtivas do conjunto de fazendas e sua implantação ao longo do curso do rio, na bacia do Médio Tietê. O que se destaca neste artigo é justamente o conjunto rural, originário de uma rica cultura agrária, e histórico, subutilizado, prenhe de elementos arquitetônicos significativos, alguns em abandono, mas que em seu todo podem compor na região um parque fluvial.

Essas características físicas baseadas na historicidade da região tornam as fazendas visualmente atraentes, alavancando empreendimentos baseados na valorização da paisagem, mas também traçam um limite que pode se transformar numa barreira para 0 desenvolvimento futuro. É tênue a diferença entre a alavanca e a barreira quando se trata de estabelecer o limite para o desenvolvimento local com base no patrimônio rural disperso na região do Médio Tietê. Toda a área deve ser considerada num plano diretor regional baseado na criação de um parque fluvial, e não apenas alguns edifícios, ou algumas sedes de fazendas históricas. Proteção e conservação enfrentam, assim, um desafio enorme ao confrontarem-se os interesses públicos com o particular de algumas autoridades locais em consonância com os proprietários de terra que não prezam a sustentabilidade, para quem a atenção é frequentemente voltada apenas para o desenvolvimento econômico ou imobiliário. 
O problema fundamental enfrentado por parte de quem preza o rico patrimônio cultural representado pelas fazendas históricas da região do Médio Tietê é a tensão que se estabelece entre a necessidade de se conservar a malha física (seu núcleo e sua paisagem) frente às demandas das atividades que ocorrem nesses espaços - ou que para eles são atraídas. Os problemas originam-se desta tensão básica entre preservar a malha histórica e prover os meios para os proprietários e visitantes se beneficiarem de sua conservação.

A necessária adaptação das fazendas históricas para áreas que abrigam atividades de comércio e serviços locais, centros de lazer e cultura com locais dotados de instalações educacionais e de saúde, um lugar assim, para se viver e trabalhar; podem danificar a arquitetura ou o caráter da fazenda. Podem danificar também o mosaico patrimonial que compõe a paisagem (cultural) rural da região. A decisão sobre a implantação ou não das adaptações necessárias é difícil no contexto de uma área rural histórica.

Sabe-se que as fazendas (Figura 1) são atraentes para um grande número de atividades potenciais; porém, ao mesmo tempo, há limites que causam problemas para a sua gestão em virtude do caráter histórico e de uma configuração pretensamente inalterável. Por vezes, isso pode se tornar uma barreira para o desenvolvimento local desde que não haja uma adaptação à nova realidade, sem mencionar os altos valores dos investimentos necessários para produzir e gerir suas atividades.

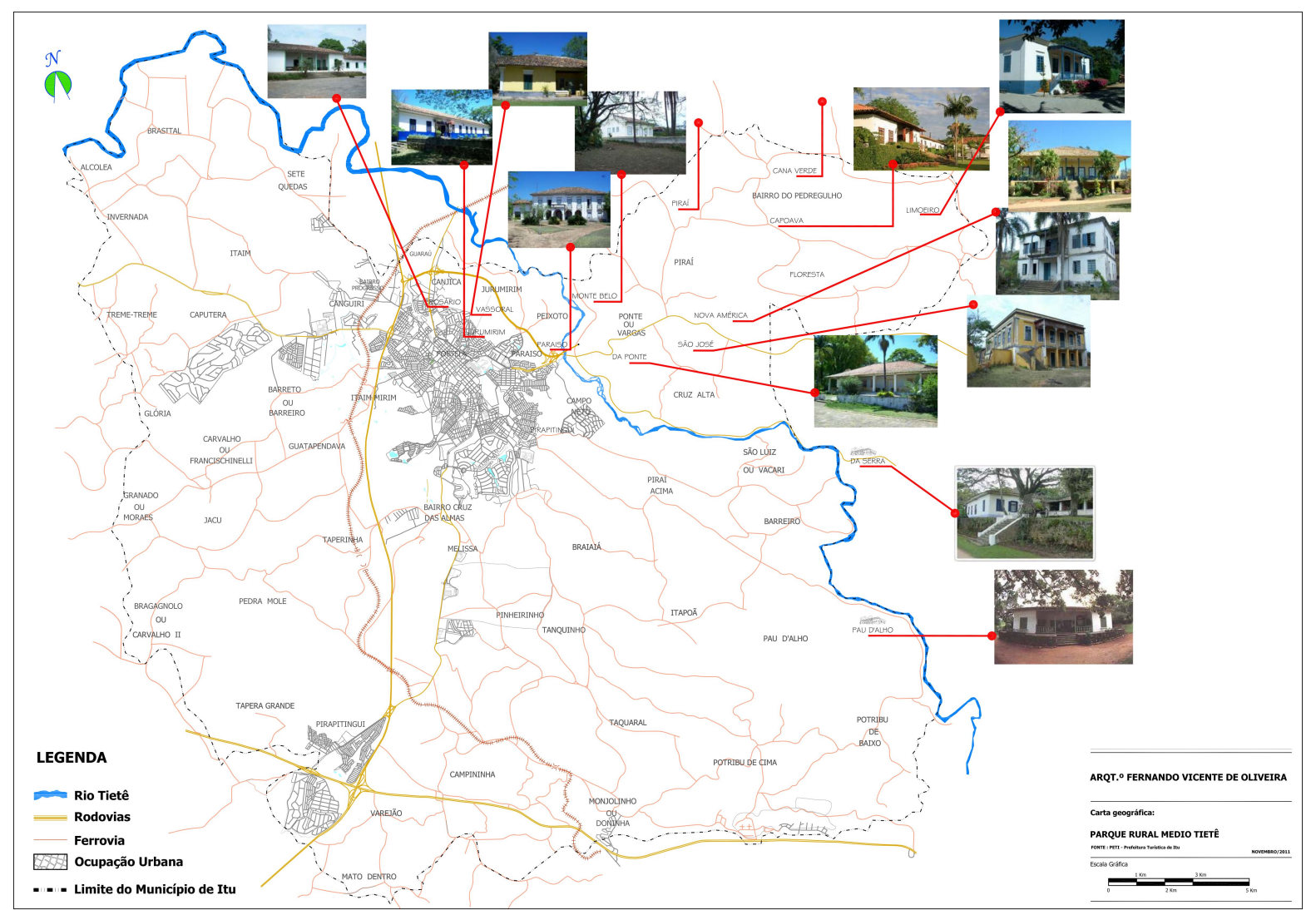

Figura 1. Elementos para o projeto de um parque fluvial com base no patrimônio rural disperso na região do Médio Tietê: sedes de fazendas históricas. Autor: Arq. Urb., M.Sc. Fernando Vicente Oliveira, 2011.

A partir do reconhecimento e valorização do significativo patrimônio arquitetônico rural disperso na região do Médio Tietê, tendo em vista as fazendas históricas existentes e o correspondente potencial de se transformarem em novas áreas de uso de lazer ou serviços, 
procurou-se elaborar uma "carta-base", destacando-se as propriedades rurais e enfatizando o rio Tietê como o condutor de percurso de um parque fluvial.

O percurso permeia um conjunto de fazendas históricas (inicialmente as 22 consideradas neste trabalho como passíveis de desempenharem o papel de unidades de interpretação, conforme o Quadro 1), propriedades de imenso valor histórico para a região do Médio Tietê. A localização destes patrimônios ao longo do rio Tietê determinou a lógica de um parque fluvial. A Figura 1 apresenta a "carta-base", elaborada também a partir de recursos fotográficos, compondo a proposta para o parque fluvial.

\section{Considerações Finais}

Pretendeu-se caracterizar o patrimônio rural como um componente fundamental da paisagem fluvial na região do Médio Tietê através de conceitos e enfoques consolidados, em contraposição com outros complementares, de maneira a evidenciá-los na forma de uma proposta projetual de um parque fluvial, conformado pela integração das fazendas históricas (inicialmente as 22 que compõem o Quadro 1) existentes na região. Entende-se por "integração das fazendas" o estabelecimento de regras comuns para a concepção de novos empreendimentos e para o uso e ocupação do solo, a partir de um plano diretor regional integrado.

O imenso patrimônio rural identificado nesta pesquisa possui relevância intrínseca tanto no contexto nacional como internacional. Ele deve ser preservado, tendo em vista o seu reconhecido valor inerente. As políticas de preservação da paisagem devem reconhecer sua história e, portanto, seu valor cultural.

Fazer de um parque fluvial o elemento modelo de projetos territoriais já não é novidade em países como a Espanha e a Inglaterra (parques rurais), Portugal e Estados Unidos, que dos parques patrimoniais se utilizam para o seu planejamento e ordenação territorial, até como forma de requalificação urbana e regional.

Este artigo permite visualizar a aplicação do conceito de parque fluvial como requisito para compor uma síntese dos conceitos de patrimônio arquitetônico de uma determinada região. $\mathrm{O}$ rio, neste caso, é o elemento que aglutina e integra o recurso natural e o cultural. Sob este ponto de vista, o patrimônio das bacias hidrográficas que compõem a região do Médio Tietê constitui-se como importante fonte de pesquisa, para além do seu caráter turístico propriamente dito, assumindo funções pedagógicas, científicas e culturais.

A força das áreas rurais na BHSMT é capaz de atrair empreendimentos e promover novos usos com base em novas atividades. A região encontra-se em um patamar bastante elevado em termos de valorização de suas potencialidades a fim de atrair investimentos, porque ela é muito bem dotada de apelo ao lazer e turismo, também por abrigar cidades históricas, consagradas e reconhecidas, além de ter uma localização privilegiada, próxima a grandes centros urbanos.

Alguns recursos patrimoniais, como edifícios históricos, coleções de objetos de arte, áreas para serviços e infraestrutura de estradas e comunicação já existem, ou podem ser criados com algum suporte financeiro. Há também a questão de atrair a atenção para as fazendas criando-se locais de visitação: marcos de referência regional. Poucos lugares no estado de São Paulo possuem um atrativo diferenciado como este que pode se tornar nacionalmente conhecido. 
Os novos usos nas áreas rurais não podem ser inteiramente absorvidos sem que se promovam as correspondentes mudanças econômicas, sociais e de estrutura física. No mundo pós-industrial, as localidades competem para atrair novas atividades e repor as que se tornaram obsoletas. Algumas têm recursos melhores, outras bem localizadas e outras ainda, um grande potencial a ser explorado. Uma alternativa viável que vem ocorrendo no Brasil são as parcerias, ou seja, os circuitos programados para unir forças e montar estratégias. Todos estes aspectos são presentes na região do Médio Tietê.

A criação de um parque fluvial pode, sobretudo, contribuir para a preservação e manutenção do rico patrimônio rural do Médio Tietê, uma vez que, sua compreensão, leitura a partir de um percurso, propicia a melhor interpretação do território sob o ponto de vista natural, social cultural, paisagístico e estético.

Finalizando, um parque fluvial no Médio Tietê se apresenta como uma ação de política pública estratégica para o desenvolvimento regional a partir da valorização das áreas rurais na BHSMT. Esta afirmação baseia-se na legislação de proteção, tanto das bacias hidrográficas, como dos bens de patrimônio cultural. Governo e iniciativa privada devem estimular tal política com articulações entre os diversos agentes da sociedade, assim como se faz em outros países. A proposta, por fim, viabilizaria economicamente as áreas rurais e históricas, por vezes obsoletas, sem recorrer à especulação imobiliária.

\section{Referências}

AB'SABER, A. N. Os domínios da natureza no Brasil: Potencialidades paisagísticas. São Paulo [SP]: Ateliê Editorial, 2003.

ARGOLLO FERRÃO, A. M. Arquitetura do café. Campinas [SP]: Editora da Unicamp; São Paulo [SP]: Imprensa Oficial do Estado de São Paulo, 2004.

BRAGA, L. M. M.; ARGOLLO FERRÃO, A. M. Arquitetura da Produção Rural: o Parque Agrário como uma possibilidade de valorização dos recursos patrimoniais para os Perímetros Irrigados do Nordeste do Brasil. Labor \& Engenho, Campinas [Brasil], v.4, n.1, p.66-77, 2010. Disponível em:

<www.conpadre.org> e <www.labore.fec.unicamp.br>.

BRASIL. Decreto-lei n ${ }^{\circ} 25$ de 30 de novembro de 1937. Organiza a Proteção do Patrimônio Histórico e Artístico Nacional. Disponível em:

<http://www.antt.gov.br/legislacao/Regulacao/suerg/Dec-lei25-37. pdf>. Acesso em: 17 ago. 2011.

CHOAY, F. Alegoria do patrimônio. São Paulo [SP]: Editora Unesp, 2001.

COORDENADORIA do Patrimônio Cultural do Estado do Paraná. Desenvolvido pela Secretaria de Cultura do Paraná: Curitiba [PR], 2010. Disponível em: <http://patrimoniocultural.pr.gov.br>. Acesso em 17/08/2011.

DECRETO n 80.978 , de 12.12.77 - Promulga a Convenção Relativa a Proteção do Patrimônio Mundial, Cultural e Natural, de 1972. Disponível em:

$<h t t p: / / w w w$.cultura.gov. br/legislacao/decretos/index. php? $p=54 \&$ more $=1 \& c=1 \& t b=1 \& p b=1>$. Acesso em 23/04/07.

FONSECA, M. C. Londres. O Patrimônio em Processo. Rio de Janeiro [RJ]: Editora UFRJ, 2005.

GOMES CARNEIRO, C. F. de Azambuja. Patrimônio Natural e valores. Secretaria de Estado da Cultura do Paraná - Coordenadoria do Patrimônio Cultural: Curitiba [PR]. Disponível em:

<http://www. patrimoniocultural.pr.gov.br>. Acesso em 16/04/2007.

ARGOLLO FERRÃO, A. M.; OLIVEIRA, F. V. Elementos para a concepção de um parque fluvial com base no patrimônio rural disperso na região do Médio Tietê. Labor \& Engenho, Campinas [Brasil] v. 6, n. 4, p. 61-71, 2012. Disponível em:

$<w w w$. conpadre.org $>$ e <www.labore.fec.unicamp.br>. 
LABOR \& ENGENHO. Revista Labor \& Engenho (2007-2012). Disponível em: <www.conpadre.org> e <www, labore.fec.unicamp>.

LARKHAM, P. J. Conservation and the city. London [U.K.]: Routledge, 1996.

LAW, C. Urban Tourism. London [U.K.]: Mansell, 1996.

LEMOS, C. A. C. O que é patrimônio Histórico? São Paulo [SP]: Editora Brasiliense, 1987.

MODENESI, M. C. Contribuição a geomorfologia da região de Itu-Salto. Dissertação de Mestrado. São Paulo [SP]: Departamento de Geografia da USP, 2008.

OLIVEIRA, F. V. Capacidade de carga em cidades históricas. Campinas [SP]: Papirus, 2003.

OLIVEIRA, F. V.; ARGOLLO FERRÃO, A. M. Caracterização do patrimônio ambiental em parques na Bacia Hidrográfica do Sorocaba Médio Tietê: cidades de Cabreúva, Itu, Salto e Porto Feliz (São Paulo). Oculum Ensaios, Campinas [Brasil], v.16, p.48-62, jul./dez., 2012.

SABATÉ BEL, J. et al. Projectant l' eix del Llobregat. Paisage cultural i desenvolupament regional. Barcelona [España]: ETSAB-UPC, 2001.

SANTOS, J. L. dos. O que é cultura? $16^{\mathrm{a}}$ ed., $10^{\mathrm{a}}$ reimpressão. Ed. Brasiliense: São Paulo [SP], 2004.

SCIFONI, S. Patrimônio mundial: do ideal humanista à utopia de uma nova civilização. Geousp, São Paulo [Brasil], v. 14, p. 77-88, 2004. Disponível em:

<http://www.geografia.fflch.usp.br/publicacoes/Geousp/Geousp14/Geousp_14_Scifoni.htm>. Acesso em 20/04/07.

SILVA, F. Fernandes da. As cidades brasileiras e o Patrimônio Cultural da Humanidade. São Paulo [SP]: Edusp; Editora Petrópolis, 2003.

TOSCANO, J. W. Diagnóstico Geral da Cidade de Itu para a implementação de um programa de ação cultural. São Paulo [SP]: CONDEPHAAT, 1977.

UNESCO. Patrimônio Natural. Disponível em:

<http://www.unesco.org.br/areas/ciencias/areastematicas/patrimonionatural/index_html/mostra_docu mento>. Acesso em 10/04/07. 